\title{
Severe Accidental Hypothermia in A Trauma Patient in A Tropical City
}

\author{
Yu-Chan Chiu', Chien-Chin Hsu², Kuo-Tai Chen ${ }^{3}$ \\ 'Department of Emergency Medicine, Chi-Mei Medical Center, Tainan, Thaiwan, China \\ 2Department of Biotechnology, Southern Tainan University of Technology, Tainan, Thaiwan, China \\ ${ }^{3}$ Department of Emergency Medicine, Taipei Medical University School of Medicine, Taipei, Thaiwan, China
}

Cite this article as: Chiu YC, Hsu CC, Chen KT. Severe Accidental Hypothermia in A Trauma Patient in A Tropical City. J Emerg Med Case Rep 2017; 8: 82-4.

\begin{abstract}
Introduction: Severe accidental hypothermia in trauma patients is rarely encountered in tropical areas. However, unnoticed hypothermia may lead to deleterious consequences and even sudden death.

Case report: We report the case of a middle-aged patient who sustained hemorrhagic shock secondary to a traffic accidentinduced severe intraabdominal injury, followed by prolonged exposure to a cold and wet environment. Thereafter, the patient was sedated and paralyzed and was administered large infusion volumes of fluid and blood components. In the emergency department, profound hypothermia could not be detected using an infrared forehead thermometer. Subsequently, the patient had a sudden cardiac arrest during the emergency surgery.

Conclusion: This case report highlights that even in a tropical city, fatal severe hypothermia may occur in severe trauma patients. Therefore, to avoid accidental hypothermia, emergency physicians and trauma surgeons should use invasive temperature monitoring, and aggressive rewarming should be performed for correcting hypothermia in severe trauma patients.
\end{abstract}

Keywords: Hypothermia, tropical, thermometer, rewarming, trauma

Received: 12.04.2017 Accepted: 08.05.2017 Available Online Date: 25.08.2017

\section{Introduction}

In tropical areas, hypothermia is not common in the emergency department (ED). A survey conducted in Queensland, Australia (a subtropical region) reported that only $7.1 \%$ of severe trauma patients developed hypothermia during hospitalization. In that study, hypothermia was defined as a body temperature of $\angle 35^{\circ} \mathrm{C}(1)$. In Poland, a country with temperate climate, severe hypothermia $\left(<28^{\circ} \mathrm{C}\right)$ cases comprised only $8 \%$ of all hypothermia patients $(2)$. Severe accidental hypothermia in trauma patients is rarely encountered in tropical areas.

Hypothermia, acidosis, and coagulopathy are a lethal triad in the management of trauma patients (3). Unnoticed hypothermia may lead to deleterious consequences and even sudden death. We report a case of a trauma patient who developed cardiac arrest that resulted from severe hypothermia, which occurred during an emergency surgery at a trauma center located in a tropical city. This case report highlights the importance of using invasive temperature monitoring and additional efforts for avoiding accidental hypothermia. Furthermore, aggressive rewarming should be performed to correct hypothermia in severe trauma patients. 


\section{Case report}

During the early morning hours of an April day, a passerby found a middle-aged male patient, who could not be identified, lying in a flooded paddy field, and a crushed motorbike was lying near him. The ambient temperature was $26^{\circ} \mathrm{C}$ at that time. On arrival at ED, the patient was disoriented and agitated (Glasgow coma scale, E4V3M5), with the following vital signs: arterial pressure, $86 / 50 \mathrm{mmHg}$; temperature, $35.2^{\circ} \mathrm{C}$ (measured using an infrared forehead thermometer); pulse rate, 62 beats/min; and respiratory rate, 15 breaths/min. Physical examination revealed multiple abrasions and bruises on the patient's face, chest, abdomen, and limbs, accompanied with a deformed and ecchymotic right arm. His skin was pale and covered with mud; his pulse was feeble.

The emergency physician infused $2 \mathrm{~L}$ of $0.9 \%$ saline to correct the shock state, and ultrasound revealed free intraabdominal fluid. Laboratory test results revealed anemia (hemoglobin, $11.6 \mathrm{~g} / \mathrm{L}$ ), severe lactic acidosis (lactate: $17.5 \mathrm{~m} / \mathrm{mole}$ ), elevated myoglobin levels (8099 $\mathrm{mg} / \mathrm{L}$ ), and alcohol level of $201 \mathrm{~g} / \mathrm{L}$. Cranial computed tomography was normal, and contrast-enhanced abdominal computed tomography showed an American Association for the Surgery of Trauma grade $\checkmark$ splenic injury with hemoperitoneum. Subsequently, the patient underwent emergency transfusion (six units of packed red blood cells and four of fresh frozen plasma) and was taken to the operating room for laparotomy. Before leaving ED, his body temperature, measured using an infrared forehead thermometer, was $36.7^{\circ} \mathrm{C}$.

During surgery, approximately $900 \mathrm{~mL}$ of intraabdominal blood was evacuated. However, sudden cardiac arrest occurred, and cardiopulmonary resuscitation with cardioversion for ventricular fibrillation was initiated. Severe hypothermia $\left(26^{\circ} \mathrm{C}\right)$ was detected after inserting an esophageal thermometer. The surgeon and anesthesiologist rewarmed the patient via an infusion of warm $0.9 \%$ saline, warm blanket coverage, heated ventilated air, and warm fluid intraabdominal lavage. The patient developed sinus rhythm and regular pulse after 10 min of resuscitation and was discharged after 22 days of hospitalization without any permanent neurological deficit.

\section{Discussion}

In our case, the accidental hypothermia was attributed to the combination of alcohol ingestion, prolonged immersion in cold water, hypovolemic shock, and anesthesia during tracheal intubation and surgery. Alcohol consumption and environmental factors are well-known causes of hypothermia in trauma patients (4). Hypovolemic shock further impaired the thermoregulatory function of the hypothalamus. Sedative and neuromuscular-blocking agents used for anesthesia impeded the physiological shivering effect $(3,4)$. If such patients are not carefully monitored, severe hypothermia may evolve unexpectedly.

Esophageal temperature assessment is the most accurate method for consistent monitoring of surgical patients (5). However, its routine use is often avoided in trauma patients, particularly in tropical areas where the incidence of accidental hypothermia is low, because inserting a thermometer is cumbersome. The Swiss staging model of hypothermia, based on the observations of vital signs at presenta- tion, allows core temperature to be estimated from clinical indicators alone (6). If a trauma patient is hypothermic (temperatures of $<35^{\circ} \mathrm{C}$ ) at admission or requires emergency surgery for hypovolemic shock, we suggest the routine use of an esophageal thermometer, accompanied with the use of the Swiss staging model of hypothermia to prevent overlooking hypothermia.

Furthermore, emergency physicians and trauma surgeons should undertake all measures to decrease heat loss while managing shock and unconscious trauma patients, including the removal of wet clothing, infusion of heated intravenous fluid and blood products, and use of external heaters (warm blankets and heated lamps). Once the patient's core temperature is $<35^{\circ} \mathrm{C}$, trauma surgeons should reduce the operative time as much as possible and provide active external and internal rewarming. In Finland and Poland, extracorporeal membrane oxygenation has been proposed as a final resort for treating refractory profound hypothermia $(2,7)$. Prolonged cardiopulmonary resuscitation combined with extracorporeal membrane oxygenation has successfully revived accidental hypothermic patients in cardiac arrest $(7,8)$.

\section{Conclusion}

This case report highlights that even in a tropical city, fatal severe hypothermia may occur in severe trauma patients. Therefore, to avoid accidental hypothermia, emergency physicians and trauma surgeons should use invasive temperature monitoring, and aggressive rewarming should be performed for correcting hypothermia in severe trauma patients.

Informed Consent: Written informed consent couldn't be obtained due to the impossibility of reaching the patient.

Peer-review: Externally peer-reviewed.

Author Contributions: Concept - Y.C.C., K.T.C.; Design - C.C.H.; Supervision K.T.C.; Resources - Y.C.C.; Materials - Y.C.C.; Data Collection and/or Processing C.C.H., K.T.C.; Analysis and/or Interpretation - C.C.H.; Literature Search - C.C.H., K.T.C.; Writing Manuscript - C.C.H., K.T.C.; Critical Review - C.C.H.

Conflict of Interest: No conflict of interest was declared by the authors.

Financial Disclosure: The authors declared that this study has received no financial support.

\section{References}

1. Aitken LM, Hendrikz JK, Dulhunty JM, Rudd MJ. Hypothermia and associated outcomes in seriously injured trauma patients in a predominantly sub-tropical climate. Resuscitation 2009; 80: 217-23. [CrossRef]

2. Kosiński S, Darocha T, Gałązkowski R, Drwila R. Accidental hypothermia in Poland-estimation of prevalence, diagnostic methods and treatment. Scand J Trauma Resusc Emerg Med 2015; 23: 13. [CrossRef]

3. Perlman R, Callum J, Laflamme C, Tien H, Nascimento B, Beckett A, et al. A recommended early goal-directed management guideline for the prevention of hypothermia-related transfusion, morbidity, and mortality in severely injured trauma patients. Crit Care 2016; 20: 107. [CrossRef]

4. Brown DJ, Brugger H, Boyd J, Paal P. Accidental hypothermia. N Engl J Med 2012; 367: 1930-8. [CrossRef] 
5. Cork RC, Vaughan RW, Humphrey LS. Precision and accuracy of intraoperative temperature monitoring. Anesth Analg 1983; 62: 211-4. [CrossRef]

6. Deslarzes T, Rousson V, Yersin B, Durrer B, Pasquier M. An evaluation of the Swiss staging model for hypothermia using case reports from the literature. Scand J Trauma Resusc Emerg Med 2016; 24: 16. [CrossRef]
7. Silfvast T, Pettilä V. Outcome from severe accidental hypothermia in Southern Finland--a 10-year review. Resuscitation 2003; 59: 285-90. [CrossRef]

8. Darocha T, Kosiński S, Jarosz A, Drwila R. Extracorporeal Rewarming From Accidental Hypothermia of Patient With Suspected Trauma. Medicine (Baltimore) 2015; 94: e1086. [CrossRef] 